\title{
Atuação dos pais na prevenção da hipertensão arterial - uma tecnologia educativa em saúde
}

\author{
Parents' actions for prevention of arterial hypertension \\ - educational technology for health
}

Zélia Maria de Sousa Araújo Santos ${ }^{1}$

Joselany Afio Caetano ${ }^{2}$

Francisco Getúlio Alves Moreira ${ }^{3}$

${ }^{1}$ Programa de PósGraduação em Saúde Coletiva, Universidade de Fortaleza (UNIFOR). Av. Washington Soares 1321

Edson Queiroz. 60.811-905 Fortaleza CE.

zeliasantos@unifor.br

${ }^{2}$ Programa de Pós-

Graduação em Enfermagem,

Universidade Federal do

Ceará (UFC)

${ }^{3}$ Departamento de Educação

Física, Faculdade Nordeste

(FANOR)

\begin{abstract}
This participatory research aimed to evaluate behavioral changes in fifteen parents of pre-school children to prevent the risk factors of arterial hypertension, by applying education technology for health that is based on the Health Beliefs Model at a private school in Fortaleza, State of Ceará, Brazil. The field research was carried out through educational workshops and data collection through questionnaires and interviews. After organizing the data into categories, analysis was based on the premises of health education. Through the application of education technology for health, significant changes were observed in the parents' habits, besides the roles they assumed as agents of change and multipliers of educational actions in the family. Although difficulties arose in the process of change, the parents were motivated to prevent the risk factors of arterial hypertension in themselves and their children. Thus, education technology for health based on the Health Beliefs Model proved to be efficient, as significant behavioral changes occurred and the parents were motivated to prevent arterial hypertension by means of a healthy lifestyle.
\end{abstract}

Key words Hypertension, Lifestyle, Risk factors
Resumo Pesquisa participante com o objetivo de avaliar as mudanças comportamentais em quinze pais de alunos do pré-escolar na prevenção dos fatores de risco da hipertensão arterial, a partir da aplicação de uma tecnologia educativa em saúde com base no Modelo de Crenças em Saúde, em uma escola privada de Fortaleza-CE. A pesquisa de campo foi realizada por meio de oficinas educativas e a coleta de dados via questionários e entrevistas. Após se organizar os dados em categorias, fundamentou-se a análise nos pressupostos da educação em saúde. Com a aplicação da tecnologia educativa em saúde, constataram-se mudanças significativas nos hábitos dos pais, além dos papéis assumidos - agente de mudança e de multiplicador das ações educativas na família. Contudo houve dificuldades no processo de mudança, mas os pais estavam motivados para a prevenção dos fatores de risco da hipertensão arterial em si e nos filhos. Então, essa tecnologia educativa embasada no Modelo de Crenças em Saúde, mostrouse eficiente, pois ocorreram mudanças comportamentais significativas, bem como motivação dos pais para a prevenção da hipertensão arterial mediante um estilo de vida saudável.

Palavras- chave Hipertensão, Estilo de vida, Fatores de risco 


\section{Introdução}

Estudos epidemiológicos têm mostrado aumento da prevalência da hipertensão arterial sistêmica (HAS) na faixa etária pediátrica ${ }^{1}$, enquanto outros estudos tem evidenciado nesta população, uma prevalência de $1 \%$ a $11 \% \%^{2,3}$. É importante o reconhecimento desta realidade para a atuação precoce na prevenção dos eventos cardiovasculares, pois a alteração da pressão arterial na infância pode ser um fator preditivo de HAS na vida adulta.

Entre os diversos fatores que contribuem para o surgimento da HAS, existem os fatores de risco constitucionais - idade, sexo, raça/cor e história famíliar -, e também os fatores de risco ambientais - sedentarismo, sobrepeso/obesidade, consumo de alimentos insalubres (excesso de sal, gordura animal, preferência por carboidratos simples e complexos, ingestão diária acima de $100 \mathrm{ml}$ de café ou de bebidas que contém cafeína, uso abusivo de álcool, estresse não gerenciado e tabagismo ${ }^{4}$.

Nas últimas décadas diversos fatores têm influenciado na mudança de estilo de vida das crianças e adolescentes. Destacam-se o crescimento imobiliário, que reduziu as áreas de lazer, e a marginalização, que induziu os pais a não deixarem seus filhos brincarem nas praças e no meio da rua. Essa redução do esforço físico gerou diminuição de gasto energético, substituído por muitas horas diante da televisão ou do computador. Fortemente aliado a esse problema, houve mudança de padrão alimentar, como a oferta de alimentações rápidas e muito calóricas (fast food), alimentos industrializados e alimentação fora de casa. Tais fatores ajudaram a produzir uma geração cada vez mais obesa e sedentária. A obesidade e o sedentarismo estão associados às principais causas das doenças cardiovasculares.

Conforme sabemos, a cada ano as crianças e adolescentes estão mais vulneráveis aos fatores de risco favoráveis ao surgimento da HAS, tais como sedentarismo, aumento de peso, hábitos alimentares inadequados, entre outros. Um dos fatores a contribuir para o excesso de peso são as cantinas escolares, por oferecerem alimentos de péssima qualidade nutricional para as crianças, tais como salgados fritos, alimentos industrializados, refrigerantes, doces, balas e chicletes. Desse modo, é difícil e até dolorosa a modificação de comportamentos e a manutenção dessas mudanças nas interações cotidianas das famílias. Pelos motivos mencionados, é importante serem desenvolvidas estratégias de prevenção mais efetivas entre os pais.
Com base no pressuposto segundo o qual por meio da educação em saúde poderíamos estimular comportamentos, valores e atitudes entre os indivíduos, iniciou-se um processo de reflexão sobre como poderíamos buscar informações sobre comportamentos, valores, crenças e atitudes dos pais diante dos fatores de risco para HAS, com vistas ao planejamento de programa educativo para a população em estudo.

Sendo assim, urge criar programas educativos que informem e conscientizem os pais a adotarem comportamentos saudáveis para minimizarem os fatores de risco da HAS na família.

Em face da problemática da HAS em crianças, alguns questionamentos pertinentes surgiram: Será que os filhos estão reproduzindo os hábitos dos pais? Será que os pais adotam condutas preventivas dos fatores de rico da HAS? Será que os pais conhecem esses fatores de risco? $\mathrm{Na}$ condição de instituição promotora de saúde, como a escola pode contribuir para a prevenção desses fatores de risco?

Ao refletir sobre estas questões, decidimo-nos pelo Modelo de Crenças em Saúde (MCS), pois esse procura explicar a adoção de comportamentos preventivos ao estabelecer relações entre o comportamento individual e algumas crenças individuais ${ }^{6}$. De acordo com o preconizado pelo MCS, há quatro percepções relevantes para aceitar intervenções médico-sanitárias: a suscetibilidade, a severidade, os benefícios e as barreiras. Como mostra a literatura, indivíduos que não se sentem vulneráveis a uma doença não costumam aceitar as medidas preventivas recomendadas ${ }^{7}$.

Um dos ambientes mais propícios à educação alimentar são as escolas. Portanto, elas podem contribuir para a promoção da saúde, o bem-estar e a qualidade de vida de toda a comunidade educacional. Para isto, devem sugerir às suas cantinas oferecerem um cardápio rico em nutrientes e menos calórico, sob orientação de um nutricionista. Embora não possam impedir as crianças de trazerem os alimentos insalubres citados anteriormente, podem promover um trabalho de conscientização permanente, por meio de informações educativas, envolvendo professores, pais, alunos e responsáveis pelas cantinas.

O presente estudo teve como objetivo analisar as mudanças comportamentais ocorridas nos pais, na prevenção dos fatores de risco da HAS, a partir da aplicação de uma tecnologia educativa em saúde embasada no Modelo de Crenças em Saúde. 
O trabalho se desenvolveu através da pesquisa participante, cuja abordagem processual de articulação de um conhecer e agir contribui diretamente para resolução de problemas de interesse coletivo, que tem como princípio fundamental uma forma de participação onde todos pesquisadores e população são sujeitos de um mesmo processo de exercício de cidadania objetivando a transformação social ${ }^{8}$. E foi desenvolvido em um colégio particular, em Fortaleza-CE, com quinze pais de alunos do pré-escolar (3 a 6 anos). Mediante convite, solicitamos seu consentimento livre e esclarecido para participarem como sujeito da pesquisa, assegurando sigilo, anonimato e liberdade de desistência de participação em qualquer momento.

Para a seleção dos sujeitos, adotamos o critério de voluntariedade e de interesse pela temática. Para a preservação do anonimato adotamos o seguinte critério: usamos a letra $S$ (de sujeito), seguida do número respectivo $(1,2 \ldots 15)$ de cada um.

Desenvolvemos este estudo sob a forma de oficinas, no total de dez, ocorridas durante os meses de janeiro a abril de 2007. Inicialmente aplicamos um questionário, contendo os dados sociodemográficos e sanitários, conhecimento e identificação dos fatores de risco da HAS e condutas preventivas desses na família. Finalmente, foram aprazados os dez encontros semanais com duração de sessenta minutos, destinados à aplicação da Tecnologia Educativa em Saúde (TES). A TES foi elaborada com base no referencial teórico do Modelo de Crenças em Saúde ${ }^{7}$ e nos pressupostos da educação em saúde.

$\mathrm{Na}$ segunda etapa, aplicamos a TES, seguindo o recomendado pelo $\mathrm{MCS}^{7}$, que tem como premissa que o mundo perceptual da pessoa determina o seu comportamento, não o ambiente físico, o que é demonstrado por quatro dimensões ou variáveis: suscetibilidade percebida; severidade percebida; benefícios percebidos e barreiras percebidas. O potencial para ação resulta da combinação das variáveis susceptibilidade e severidade percebidas na doença, enquanto a modalidade de ação é escolhida em função da percepção dos benefícios, excluindo-se as barreiras percebidas nos comportamentos em saúde 9 . A seguir segue a descrição da TES:

Primeiro e segundo encontros. Abordamos as seguintes percepções - suscetibilidade e severidade da HAS, com a finalidade de informar os sujeitos e de despertá-los para a HAS, fatores de riscos, complicações, morbidade e mortalidade.
Terceiro e quarto encontros. Exploramos as percepções - as barreiras e os benefícios da mudança, quanto à prevenção dos fatores de risco da HAS, por meio da dinâmica papel amassado ${ }^{10}$, com o objetivo de possibilitar aos participantes a percepção das dificuldades para inserir hábitos saudáveis no seu estilo de vida.

Quinto encontro: Abordamos a importância da alimentação saudável, em uma oficina educativa planejada com uma nutricionista, utilizando a dinâmica do repolho ${ }^{10}$, com a finalidade de reafirmar os benefícios da mudança.

Sexto encontro. Colaboramos no planejamento e na implementação de uma oficina intitulada Gerenciamento do Estresse, coordenada por uma psicóloga, como uma das estratégias para a adoção de um estilo de vida saudável, com vistas à prevenção da HAS.

Sétimo encontro. Auxiliamos uma enfermeira especialista e pesquisadora em dependência química na organização e realização de uma sessão interativa sobre prevenção e combate à dependência química (drogas lícitas e ilícitas).

Oitavo e nono encontros. Discutimos as várias alternativas para o combate ao sedentarismo, entre elas a prática regular do exercício físico anaeróbio, com o objetivo de ressaltar sua importância na prevenção e controle da HAS, além de orientar a prática das suas diversas modalidades, destacando as indicações, contraindicações e critérios para essa prática. Encerramos esses encontros com a vivência da caminhada e da hidroginástica. Estes encontros foram coordenados pelo educador físico.

Décimo encontro. Neste, desenvolvemos a última etapa do MCS - motivação para mudanças, com a construção de um plano de metas, pelos sujeitos, com as mudanças necessárias à prevenção dos fatores de risco da HAS, no ambiente familiar e escolar. Durante a pesquisa de campo, usamos o diário de campo para o registro de informações relevantes para a complementação da análise dos dados.

Na terceira etapa fizemos duas entrevistas com o objetivo de avaliar as mudanças ocorridas com a aplicação da TES. A primeira entrevista foi realizada um mês após a aplicação da tecnologia e a segunda, dois meses depois.

De posse desses dados, os resultados foram organizados em categorias empíricas e analisados conforme a técnica de análise de conteúdo de $\operatorname{Bardin}^{11}$, fundamentando-se nas experiências vivenciadas pelos sujeitos na aplicação da TES, no referencial teórico de Beck $^{7}$ e nos pressupostos da educação em saúde. 
Dessa forma, o conceito de Educação em Saúde está ancorado no conceito de promoção da saúde, que trata de processos que abrangem a participação de toda a população no contexto de sua vida cotidiana e não apenas das pessoas sob o risco de adoecer. Essa noção está baseada em um conceito de saúde, considerado como um estado positivo e dinâmico de busca de bem-estar, que integra os aspectos físicos e mentais (ausência de doença), ambiental, pessoal e social ${ }^{12,13}$.

As ações de Educação em Saúde encontram-se vinculadas ao exercício da cidadania na busca por melhores condições de vida e de saúde da população, principalmente quando perpassam todas as fases do atendimento, promovendo espaços de troca de informação, permitindo identificar as demandas de saúde dos usuários e as escolhas mais adequadas e diminuindo a distância habitual entre profissionais de saúde e populaçãa ${ }^{13}$.

As categorias que emergiram foram: a percepção dos pais quanto à suscetibilidade à doença hipertensiva; estímulo externo influenciando a busca de um estilo de vida saudável; os benefícios e as barreiras percebidos para a busca de um estilo de vida saudável; fatores estruturais e sociais influenciando na busca de um estilo de vida saudável.

Quanto aos aspectos ético-legais desta pesquisa, cumprimos as recomendações da Resolução 196/96 da Comissão Nacional de Ética em Pesquisas - $\mathrm{CONEP}^{14}$, e a pesquisa foi realizada após parecer favorável do Comitê de Ética da Universidade de Fortaleza (UNIFOR) e da assinatura do termo de consentimento livre e esclarecido pelos sujeitos.

\section{Análise e discussão dos dados}

\section{Caracterização dos sujeitos}

Os sujeitos estavam na faixa etária de 35 a 66 anos, oito de 40 a 47 anos, quatro de 35 a 38 anos, um de 55 anos e um de 66. Destes, onze eram mulheres e quatro eram homens. Do total, doze procediam de Fortaleza-CE, e três de outros municípios do Estado. Treze eram casados e duas solteiras. Onze tinham dois filhos, três tinham um filho e um tinha cinco filhos. Treze moravam em companhia do cônjuge e filhos, um residia somente com o filho e um com o filho e avós. Onze tinham nível superior e quatro o ensino médio. Seis ganhavam entre onze e quinze salários mínimos, seis entre sete e dez, três entre dois e cinco. Em relação à ocupação, havia qua- tro professores, dois bancários, três prendas do lar, um empresário, um aposentado, uma contadora, um comerciante, um estudante. Todos eram de religião católica.

\section{Apresentação das categorias \\ e discussão dos temas obtidos}

\section{Percepção dos pais quanto}

à suscetibilidade à síndrome hipertensiva

A intensidade do estímulo necessário para iniciar a ação depende da percepção da suscetibilidade e da severidade da doença. Portanto, se o indivíduo não se julgar vulnerável para contrair a doença precisará de um estímulo maior para iniciar o processo de mudança.

Como fatores de risco presentes nos participantes do estudo identificamos: idade; histórico familiar; obesidade; raça; hábito alimentar, com consumo de gordura animal e também ingestão excessiva de café; consumo de bebidas alcoólicas; dificuldade no gerenciamento do estresse e sedentarismo.

Ao serem indagados, os sujeitos revelaram algum conhecimento prévio sobre os fatores de risco da HAS e das condutas preventivas desse agravo. Possivelmente este fato está relacionado com as experiências vividas e com o nível de escolaridade, conforme percebemos nos relatos.

"[...] excesso de sal nos alimentos, sedentarismo, estresse, tabagismo, podem aumentar hipertensão arterial". (S13)

"[...] eu sei que a hipertensão arterial é doença hereditária, e que também pode ser causada pelo uso de bebidas alcoólicas, diabete, obesidade e tensão emocional". (S 8)

"[...] sei que os exercícios físicos e uma alimentação balanceada ajudam a prevenir a hipertensão, mas precisamos de mais conhecimentos para implementação de forma mais segura e para motivar algumas mudanças no nosso estilo de vida" (S10)

“[...] para prevenir a hipertensão são necessárias as condutas: evitar o álcool e o cigarro, controlar as tensões nervosas, evitar aborrecimentos desnecessários"(S 5)

Embora a percepção de benefícios quanto à adoção de medidas de prevenção e controle da hipertensão arterial não implique necessariamente na coerência e na efetividade da ação, a crença é, por si só, um forte previdente do comportamento. De acordo com o Modelo de Crenças em Saúde, a pessoa, para mudar comportamentos de saúde, necessita primeiramente valorizar os benefícios das mudanças de estilo de vida, ou seja, 
acreditar que é possível reduzir a suscetibilidade ou severidade da doença ${ }^{9}$.

Segundo mostra o MCS, em relação à suscetibilidade percebida, as pessoas variam muito quanto à aceitação da possibilidade de fazer parte de determinada condição. Enquanto num extremo, certos indivíduos negam qualquer possibilidade de se enquadrar em dada condição, em outro alguns podem admitir esta possibilidade, embora improvável, e, finalmente, existem os que podem expressar a possibilidade real de estar em perigo quanto à doença. Tal percepção poderá influenciar positivamente ou negativamente a busca por tratamento. De modo geral, estas percepções são influenciadas por variáveis demográficas (sexo, idade, raça, condições socioeconômicas e culturais); varáveis psicossociais (personalidade, classe social, etc.); variáveis estruturais (conhecimento sobre a doença, contato anterior) ${ }^{7}$. Nos relatos a seguir, sobressaem estas percepções.

“[...] eu não sabia que filhos de pais hipertensos têm um risco maior de serem hipertensos. Meu esposo é hipertenso, e isso passou a me preocupar com os meus filhos". (S2)

“[...] eu e meu marido somos gorduchos. Então temos risco de nos tornar hipertensos [...] e até meus filhos, porque também são gordos e a nossa comida é bem salgada e gordurosa”. (S 12)

A percepção da suscetibilidade diante de familiares com hipertensão arterial ou fatores de riscos, aliada à educação em saúde para aquisição de novos conhecimentos, pode ajudar os pais na aquisição de hábitos saudáveis de saúde.

Nesse caso, a severidade identificada é uma variável relacionada à percepção da seriedade de dada condição de saúde. Como afirma a literatura, o grau de seriedade pode ser julgado pelo grau de estimulação emocional criado por determinadas circunstâncias, tais como: ideias sobre uma doença, tipos de dificuldade atribuída pelo indivíduo ante o risco que dada condição de saúde poderá criar para ele ou mesmo pelo simples conhecimento das complicações que aquela doença poderá trazer para sua saúde e à qualidade de vida ${ }^{6}$. O efeito de sentir a severidade em contrair uma doença leva o indivíduo a avaliar os problemas clínicos, físicos e mentais provocados, as possíveis consequências sociais, ou mesmo a morte, como mostram os relatos.

“[...] perdi meu pai, pois ele teve um AVC. Meu esposo é hipertenso. O que posso fazer para ajudá-lo, para não acontecer o mesmo fim.” (S 12)

“[...] quem tem pressão alta não sente nada [.... é uma doença diferente das outras, que sem- pre a pessoa sente alguma coisa, e que incomoda. Então, a hipertensão é perigosa, porque mata em silêncio. Neste caso, é seguro evitar esta doença traiçoeira.” (S 4)

A percepção da severidade da doença constitui um fator importante e serve como estímulo para o indivíduo adotar um novo estilo de vida. Portanto, a combinação das percepções individuais de suscetibilidade de um problema de saúde e da severidade das consequências de se contrair esse problema gera uma percepção de ameaça que irá determinar uma reação no indivíduo para adotar uma ação ${ }^{6}$.

\section{Estímulo externo influenciando}

a busca de um estilo de vida saudável

Como ressalta o MCS, existem estímulos que influenciam o processo de tomada de decisão ao funcionarem como fatores modificadores da ação sobre a ameaça percebida de determinada doença. Tais estímulos relacionam-se a conselhos de terceiros, lembretes escritos de profissionais de saúde, experiências de membros da família, bem como outros meios de informação ${ }^{15}$. Neste estudo desenvolvemos uma tecnologia educativa com base nos indicadores de um estilo de vida saudável - alimentação saudável, gerenciamento do estresse, abstinência do álcool e do tabaco e combate ao sedentarismo, compatíveis com a prevenção e/ou controle dos fatores de risco da HAS.

A alimentação saudável consiste de um cardápio diário com predomínio de vegetais e de carnes brancas, exclusividade no uso de gordura vegetal, redução de carboidratos simples e complexos, e de sal (no cozimento e na abolição de embutidos e enlatados), e refeições fracionadas. Para a prevenção da HAS exige-se mudança de hábitos, tal como reeducação alimentar. Com esta finalidade, é preciso evitar alimentos gordurosos, diminuir a ingestão de sal e adotar a prática de exercícios físicos ${ }^{16}$.

Outro indicador de estilo de vida saudável foi gerenciamento do estresse explorado em uma oficina conduzida por uma psicóloga. Nesta oficina discutimos os estressores frequentes, entre os quais sobressaem: educação dos filhos, trabalho e trânsito. Foram propostas as estratégias sobre como evitá-los ou controlá-los.

De modo geral, o alcoolismo e o tabagismo são vícios frequentes entre as pessoas, sobretudo os jovens. O consumo de grandes quantidades de bebidas alcoólicas causa danos sociais e relaciona-se ao risco elevado da hipertensão arterial ${ }^{17}$. Mesmo assim, a droga mais relatada no ambi- 
ente familiar foi o álcool. Ao longo da oficina, a prevenção e o combate aos vícios e à dependência química destes foram discutidos entre os sujeitos, com intermediação de uma enfermeira especialista nesse mal.

Finalmente, no combate ao sedentarismo, a prática regular do exercício físico foi abordada por um educador físico, em dois momentos: resgate teórico-prático das experiências prévias, para nortear a construção coletiva de um novo saber; e vivência em duas modalidades de exercício físico aeróbico - caminhada e hidroginástica.

Considerando que as mudanças comportamentais representam o abandono de alguns prazeres, é necessário que a educação em saúde se faça de modo a contemplar a individualidade e o contexto social da pessoa. É importante também que os educadores em saúde exerçam a função de encorajar os indivíduos hipertensos a assumir a responsabilidade de proteção da saúde, de ajudar a encontrar, no âmbito das suas possibilidades, a adoção de hábitos de vida saudáveis, no intuito de promover o controle e a prevenção de agravos da doença ${ }^{9}$.

\section{Os benefícios e as barreiras percebidos}

para a busca de um estilo de vida saudável

De acordo com definição do MCS, a suscetibilidade e a severidade percebidas podem conduzir à tomada de uma ação, mas não definem a ação a ser tomada. Tal ação dependerá das crenças do indivíduo em relação à efetividade das alternativas conhecidas para tomada de decisão. Seu comportamento dependerá, então, da crença do quão benéficas, para o seu caso, serão as várias alternativas para reduzir a ameaça a cada condição de saúde ${ }^{7}$.

Enquanto os benefícios percebidos referemse à crença na efetividade da ação e à percepção de suas consequências positivas, as barreiras percebidas referem-se aos aspectos negativos da ação, os quais são avaliados em uma análise tipo custo-benefício ${ }^{7}$. Na pesquisa ora elaborada algumas barreiras foram facilmente observadas, como custo de dinheiro, tempo e esforço.

Durante e após a oficina educativa facilitada por uma nutricionista, os pais questionaram sobre os possíveis custos ou barreiras à adoção de hábitos saudáveis, como mostram os depoimentos dos sujeitos da pesquisa.

"[...] é muito difícil implementar as mudanças dos hábitos, principalmente devido a força da mídia para vender os alimentos hipercalóricos, chilitos, chocolates, sanduíches" (S 4)
“[...] porque a escola não trabalha mais a importância da alimentação saudável com os alunos"? (S 6)

“[...] não compro refrigerantes para casa, mas as cantinas do colégio oferecem salgados, refrigerantes. O quê fazer"? (S 12)

Neste sentido, sugerimos às escolas desenvolverem atividades educativas desde a educação infantil, para formar um conhecimento crítico sobre a alimentação saudável, pois na infância muitos hábitos prejudiciais à saúde ainda não foram aprendidos. Para isso, torna-se importante a capacitação dos professores e pais, com vistas à massificação das informações para a promoção da saúde. Contudo, as cantinas podem incentivar o consumo de alimentos mais saudáveis, mediante uma diversificação maior de produtos de qualidade nutricional.

Os hábitos alimentares, os exercícios físicos e o lazer relacionam-se especialmente aos costumes do contexto familiar, e as mudanças sobre este estilo de vida podem ocorrer gradualmente, de acordo com o fator tempo e as mudanças dos suprassistemas ao redor, sobretudo família/escola ${ }^{18}$.

Muitas vezes, a percepção das barreiras pode agir como impedimentos para a adoção dos comportamentos e pode gerar conflitos na tomada de decisão ${ }^{19}$. Entretanto, se os aspectos positivos forem mais fortes e os negativos mais fracos, a ação preventiva será concretizada. Por serem os pais os principais educadores, eles deverão ser os primeiros a adotar hábitos saudáveis, e a incentivar os filhos a adotá-los.

Quanto ao gerenciamento do estresse, os sujeitos indicaram condutas gerenciadoras desses estressores, como segue nas falas:

"[...] trânsito engarrafado; combater saindo mais cedo de casa; preocupação com a saúde dos filhos; combater levando aos especialistas". (S 10)

"[...] ensinar tarefas dos filhos; solucionar desenvolvendo autonomia para que eles sejam capazes de fazerem as tarefas sozinhos e perguntar somente as dúvidas". (S 5)

"[...] carga horária excessiva no trabalho; solucionar tentando diminuí-la; desorganização dos filhos; conversar para amenizar e entendê-los". (S 14)

"[...] vivo altamente estressado; procurar ter mais lazer". (S 10)

$\mathrm{Na}$ discussão sobre o alcoolismo e o tabagismo, a experiência vivida pelos participantes com esses vícios foi resgatada, conforme mostram as falas.

“[...] tenho um irmão que passa dois meses sem usar bebidas alcoólicas, mas quando volta 
passa quinze dias bebendo todo dia, quase sem se alimentar, e só para quando não aguenta mais ou precisa ir ao médico". (S 11)

"[...] o meu marido bebe muito. Isso me incomoda”. (S 13)

Para combater o alcoolismo e o tabagismo, os pais precisam comunicar-se mais com os filhos. Compete-lhes passar informações sobre os malefícios destas drogas e tentar serem mais amigos dos filhos. Como revela o dia-a-dia, quando estes não encontram a afetividade e o equilíbrio no ambiente familiar, muitas vezes recorrem às drogas como forma de refúgio. A família, principalmente os pais, precisa dar apoio e bons exemplos.

O comportamento de um familiar afeta o comportamento do outro membro da família. Desse modo, o alcoolismo do marido pode desenvolver a gastrite emocional do filho e a hipertensão arterial da mãe $e^{18}$.

São muitos os benefícios do exercício físico e entre estes incluem-se: melhorar a aptidão física do individuo, aumentando sua capacidade aeróbica e sua resistência cardiovascular; promover o controle das situações de estresse; elevar a autoestima e auxiliar na manutenção e na perda de peso. Entretanto, apesar dos estudos e divulgações sobre as evidências dos benefícios do exercício físico na prevenção e controle de doenças, crescem a cada dia o sedentarismo e as doenças a ele relacionadas ${ }^{20}$. De acordo com o observado, as mudanças comportamentais, principalmente em relação ao combate ao sedentarismo, constituem um processo lento. Por isso, necessitam de uma constante interação dos profissionais de saúde com vistas a orientar e a estabelecer um ambiente de confiança, com ênfase nos benefícios e nos resultados obtidos pelo indivíduo mediante aquisição de hábitos saudáveis. As falas a seguir confirmam estas palavras.

“[..] acho importantíssimo o exercício físico, em vez de tomar remédio para emagrecer e ficar cheio de pelanca". (S 12)

"[...] achei fantástico. Nunca tinha feito hidroginástica. A gente relaxa mesmo, deve ser muito bom para aliviar o estresse”. (S 11)

Fatores estruturais e sociais influenciando na busca de um estilo de vida saudável

Determinados fatores modificam a percepção individual e influenciam indiretamente na ação final, tais como aspectos psicossociais (personalidade, classe social, pressão social) e estruturais (conhecimento sobre a doença, contato anterior com a doença $)^{15}$.
No referente aos aspectos psicossociais, chamaram-nos atenção as características do sujeito do estudo e os fatores de risco para HAS; quanto aos estruturais, sobressaíram a perda dos familiares, a própria vivência com a HAS e o envolvimento dos pais no processo educativo desenvolvido neste estudo.

Por serem os principais educadores no lar, os genitores podem contribuir para a prevenção da hipertensão arterial neste ambiente. Ao mesmo tempo, a escola, como agente de transformação social, será capaz de mobilizar ações que concretizem os ideais da promoção da saúde, capacitando os pais para atuarem como promotores da saúde dos próprios filhos ${ }^{21}$.

"[...] passei a caminhar, também levo meu filho junto, comecei a implementar o lanche saudável [...] passei a ter uma alimentação mais saudável e a cobrar do marido para diminuir de beber e fumar". (S 1)

"[...] eu faço musculação, mas meu filho e esposo estão acima do peso. Estou balanceando mais a alimentação deles e incentivando a prática de exercícios físicos [...] passamos a ter mais consciência da importância da implementação de hábitos saudáveis para prevenir doenças, entre elas a hipertensão". (S 12)

Como observamos, os pais revelaram-se agentes multiplicadores do saber sobre a prevenção da HAS na família. É nesta que as pessoas têm o primeiro contato com a educação. Logo, os pais são os atores pioneiros no processo educativo. Contudo, a missão de educador não tem prazo definido, e, a exemplo da aprendizagem, é algo inesgotável. No cotidiano, somos sempre agentes de mudança e multiplicadores.

"[...] passei a refletir sobre minha qualidade de vida e procurei passar conhecimentos para os filhos e esposo [...] meu esposo passou a caminhar todos os dias e a alimentar-se de forma mais saudável". (S 2)

"[...] com os conhecimentos que massifiquei [...] meu marido diminuiu a bebida [...] estou tentando que os meus filhos tenham uma alimentação mais saudável e façam exercícios físicos". (S 3)

"[...] tivemos uma recaída em virtude de um problema de saúde na família, mas continuamos convictos da importância vital de alimentação saudável e prática regular de exercício fisco para evitar doenças". (S 5)

"[...] passamos a ter mais consciência da importância da implantação de hábitos saudáveis para prevenir doenças, entre estas, a hipertensão". (S 12) 
“[...] minha esposa e meus filhos passaram a valorizar a alimentação saudável e a prática regular do exercício fisco". (S 14)

"[...] estou firme nas minhas mudanças. Estou fazendo exercícios físicos e tendo uma alimentação mais saudável, mas ainda continuo implementando as mudanças junto aos filhos e esposo". (S 10)

Evidenciamos nestes depoimentos pais motivados a promover a saúde mediante hábitos saudáveis, envolvendo os filhos e outros familiares neste processo. Portanto, a mudança implica em si mesma uma constante ruptura, ora lenta, ora brusca, da inércia à estabilidade.

Após dois meses da aplicação da TES, ocorreram mudanças significativas nos indicadores de estilo de vida saudável nos pais e na família, conforme demonstrado nas falas:

"[...] coloco mais verduras na minha alimentação e das crianças, tirei o excesso de gorduras, diminuí o sal, pois sou hipertensa”. (S 7)

"[...] passei a gerenciar as compras do mercantil, colocando mais frutas, adoçante dietético, verduras [...] evitando enlatados, embutidos e industrializados [...] vamos tirar um tempo para fazer exercícios e os meninos andarem de bicicleta. Aos poucos a gente tava mudando". (S 13)

"[...] continuo diminuindo o sal, usando mais verduras e vegetais na alimentação”. (S 7)

"[...] continuo as minhas caminhadas, e incentivo minha esposa a caminhar comigo". (S 11)

"[...] continuo fazendo exercícios regularmente. As crianças passaram a fazer natação e meu marido iniciou o ciclismo". (S 6)

"[...] passei a gerenciar melhor meu estresse mediante as várias opções de lazer “. (S 13)

“[...] incluí o planejamento e a organização no meu dia-a-dia. Desse modo, consegui gerenciar meu estresse e evitei difundi-lo na minha família”. (S15)

"[...] decidi eu mesmo fazer o almoço, para fins de inserir mais alimentos saudáveis”.(S 8)

"[...] sinto-me mais disposto, me canso menos, descanso melhor. Acho que é mais saúde que tenho com a mudança de hábitos”. (S 11)

De acordo com o exposto nas falas, o combate ao sedentarismo constituiu uma das metas atingidas pelos sujeitos e por seus familiares. Determinados estudos epidemiológicos demonstram associação inversa entre exercícios físicos e a $\mathrm{HAS}^{20}$. A caminhada é recomendada por ser uma atividade física rítmica, repetitiva e que desafia os limites do sistema circulatório, mas com uma intensidade adequada e individualizada ${ }^{22}$. As IV Diretrizes Brasileiras de Hipertensão Arte- rial recomendam a frequência de 3 a 6 vezes por semana, na intensidade moderada e sessões de 30 a 60 minutos de duração ${ }^{23}$. A atividade física regular é capaz de promover um aumento na capacidade física em nível pelo menos moderado, podendo ser benéfico tanto para a prevenção, como para o tratamento da HAS. No entanto, os efeitos do treinamento não persistem por mais de 2 semanas, após a interrupção da atividade física regular ${ }^{22}$.

Entre os vícios, o alcoolismo foi o único relatado por cinco pais inicialmente. Entretanto, após o período de acompanhamento, quatro aboliram este vício. A exemplo do alcoolismo houve redução também do tabagismo, especificamente por familiares de três sujeitos. O uso excessivo de álcool leva à falta de controle da pressão arterial, causando alterações significativas nos níveis pressóricos, embora seus efeitos sejam reversíveis ${ }^{24}$.

Como um dos problemas mais frequentes mencionamos o estresse, considerado fator de risco para HAS. Portanto, uma das condutas preventivas deste risco é o seu gerenciamento mediante prevenção e/ou controle dos fatores estressores habitualmente presentes no cotidiano de cada pessoa.

Para conscientizar as pessoas a adotarem um estilo de vida saudável, a educação em saúde torna-se um meio importante na mudança de comportamento e no exercício da cidadania. Essa mudança é viabilizada quando o profissional de saúde reconhece e valoriza o saber socialmente construído pelas pessoas em seu ambiente ${ }^{25}$.

Aos pais, como agente de mudanças, cabe a responsabilidade de dar os primeiros passos para concretizá-las. Eles podem estimular os filhos a experimentar novos hábitos a fim de incorporá-los na prática cotidiana. Os sinais percebidos dos benefícios servem como estímulos internos para dar continuidade ao processo de mudança ${ }^{22}$. Esse estímulo não deve vir apenas da educação formal, escolarizada, mas de toda ação educativa que propicie a reformulação de hábitos, a aceitação de novos valores e que estimule a criatividade.

\section{Considerações finais}

Acreditamos na influência dos pais no êxito do processo educativo dos filhos, com vistas à prevenção dos fatores de risco da HAS, sobretudo quando a comunicação entre estes é feita de maneira clara e objetiva, e nela os pais deixam transparecer sua preocupação quanto à saúde 
dos filhos e à forma encontrada por estes para mantê-la.

Segundo evidenciamos, os sujeitos revelaram algum conhecimento prévio sobre os fatores de risco da HAS e das condutas preventivas desse agravo. Algumas barreiras foram facilmente observadas: custo de dinheiro, tempo e esforço. Ainda como evidenciamos, nos depoimentos os pais estão motivados a promover a saúde por meio de hábitos saudáveis, envolvendo os filhos e outros familiares neste processo. Portanto, a mudança implica em si mesma numa constante ruptura, ora lenta, ora brusca, da inércia à estabilidade.

A tecnologia educativa implementada neste estudo com base no Modelo de Crenças em Saúde possibilitou momento de reflexão para os pais sobre a necessidade de mudanças de hábitos na família. Diante dos resultados, consideramos a TEF válida e apropriada para ser inserida nas rotinas de práticas em educação em saúde nas escolas, em parceria com os pais ou responsáveis.

\section{Colaboradores}

ZMSA Santos e FGA Moreira, trabalharam na concepção, delineamento, análise e interpretação dos dados. Caetano JA contribuiu na redação e revisão crítica do artigo, a aprovação da versão final a ser publicada. 


\section{Referências}

1. Sorof J. Daniels S. Obesity hypertension in children: a problem of epidemic proportions. Hypertension 2002; 40(4):441-447.

2. Mendes MJFL, Alves JGB, Alves AV, Siqueira PP, Freire EFC. Associação de fatores de risco para doenças cardiovasculares em adolescentes e seus pais. Rev. Bras. Saude Mater. Infant. [periódico na Internet]. [citado 2008 jul 07]. Disponível em: http:/ /www.scielo.br/scielo.php?script $=$ sci_arttext \&pid $=$ S1519-38292006000500007\&lng $=$ pt\&nrm $=$ iso. doi: 10.1590/S1519-38292006000500007

3. Morrison JA, James FW, Sprecher DL, Khoury PR, Daniels SR. Sex and race differences in cardiovascular disease risk factor changes in schoolchildren, 1975-1990: the Princeton School Study. Am J Public Health 1999; 89(11):1708-1714.

4. Santos ZMSA, Lima HP. Tecnologia educativa em saúde na prevenção da hipertensão arterial em trabalhadores: análise das mudanças no estilo de vida. Texto Context. Enferm 2008; 17(1):90-97.

5. Berenson GS, Srinivasan SR, Bao W, Newman WP 3rd, Tracy RE, Wattigney WA. Association between multiple cardiovascular risk factors and athenosclerosis in children and young adults. Bogalusa Heart Study. N Engl J Med 1998; 338(23):1650-1656.

6. Dela Coleta M. Lócus de Controle e Saúde. In: Dela Coleta M, organizador. Modelos para a pesquisa $e$ modificação de comportamentos de saúde. São Paulo: Cabral Editora Universitária; 2004. p. 199-239.

7. Becker MH. The Heart Belief Model and Personal Heart Behaviour. New Jersey: Thorofare; 1974.

8. Demo P. Metodologia científica em ciências sociais. São Paulo: Altas; 1995.

9. Pires CGS, Mussi FC. Crenças em saúde para o controle da hipertensão arterial. Cien Saude Colet 2008; 13(Supl. 2):2257-2267.

10. Jalowitzki M. Vivências para dinâmicas de grupos-a metamorfose do ser em 360 graus. São Paulo: Madras; 2004.

11. Bardin L. Análise de conteúdo. Portugal: Edições 70; 2004.

12. Moura ERF, Sousa RA. Educação em saúde reprodutiva: proposta ou realidade do Programa Saúde da Família? Cad Saude Publica 2002; 18(6):1809-1811.

13. Araújo FM. Ações de educação em saúde no planejamento familiar nas unidades de saúde da família no município de Campina Grande PB [monografia]. Campina Grande (PB): Universidade Estadual da Paraíba; 2004

14. Brasil. Conselho Nacional de Saúde. Resolução 196/ 96. Decreto no 93.933 de janeiro de 1987. Bioética 1996; 4(2):15-25
15. Lescura Y, Mamed MV. Educação em saúde: abordagem para o enfermeiro. São Paulo: Sarvier; 1990.

16. Bittar A. A atividade física como coadjuvante do tratamento da hipertensão arterial. Âmbito da Medicina desportiva 2001; 6(73):11-13.

17. Mion Júnior D, Guimarães AC, Palmeira CS, Forjaz CLM, Coelho EB, Almeida FA, Pellizari ICE. Prevenção primária segundo as IV Diretrizes Brasileiras de Hipertensão Arterial. Arq. Brasileiro de Cardiologia 2004; 82(Supl. 4):30-40.

18. Carbone MH. Estilo de vida. In: Costa EMA, Carbone MH, organizadoras. Saúde da família: uma abordagem interdisciplinar. Rio de Janeiro: Rúbio; 2004.

19. Rosenstock IM. Historical origins of the Health Belief Model. Health Educ. Monogr. 1974; 2(4):328-335.

20. Souza WKSB. Benefícios da atividade física na hipertensão arterial e orientações práticas. Rev. Brasileira de Hipertensão 2004; 11(2):115-116.

21. Catrib AMC. Saúde no espaço escolar. In: Barroso MGT, Vieira NFC, Varela MZV, organizadores. Educação em saúde no contexto da promoção humana. Fortaleza: Demócrito Rocha; 2003.

22. Silveira Júnior PCS, Martins RCA, Dantas EHM. Os efeitos da atividade física na prevenção da hipertensão. Rev Bras Med Esporte 1999; 5(2):66-72.

23. Sociedade Brasileira de Hipertensão (SBH). Sociedade Brasileira de Cardiologia (SBC). Sociedade Brasileira de Nefrologia (SBN). IV Diretrizes Brasileiras de Hipertensão Arterial. [citado 2009 jun 24]. Disponível em: http:/www.sbh.org.br/diretrizes.2002.

24. Jardim PCBV. Abordagem não-medicamentosa do paciente com hipertensão arterial. Soc. Brasileira de Cardiologia 2003; 83(3):10-19.

25. Santos ZMSA, Barroso, MGT. A interdisciplinaridade na fundamentação da promoção da saúde. In: Barroso MGT, Vieira, NFC, Varela MZV, organizadores. Educação em saúde no contexto da promoção humana. Fortaleza: Demócrito Rocha; 2003. p. 55-58.

Artigo apresentado em 14/09/2009

Aprovado em 30/06/2009

Versão final apresentada em 12/07/2009 